\title{
The Study of Nanocrystalline Cerium Oxide by X-Ray Absorption Spectroscopy
}

\author{
Ponnusamy Nachimuthu,,${ }^{*}$ Wen-Chen Shih, $\dagger$ Ru-Shi Liu, $\uparrow^{+1}$ Ling-Yun Jang,* and Jin-Ming Chen* \\ $\dagger$ Department of Chemistry, National Taiwan University, Roosevelt Road, Section 4, Taipei 106, Taiwan, Republic of China; and \\ *Synchrotron Radiation Research Center, No. 1 R\&D Road VI, Hsinchu Science-Based Industrial Park, Hsinchu 30077, Taiwan, Republic of China
}

Received August 17, 1999; in revised form October 28, 1999; accepted November 5, 1999

X-ray absorption spectroscopy has been used to study the structural and electronic properties of cerium atoms in nanocrystalline cerium oxide. These nanocrystalline cerium oxides were prepared by precipitation followed by the aging process. To increase the particle size, the as-prepared cerium oxides were calcined at various temperatures. The nanocrystalline phase was retained, even when the samples were calcined at $600 \mathrm{C}$. The analyses of X-ray absorption near edge structures (XANES) for cerium oxides show that the increase in the relative intensity of the transition to $2 p 4 f^{1} 5 d^{*} \underline{L}$ final state and its transition energy shifts toward higher energy are due to the increase in covalence between cerium and oxide ligands with increasing particle size. The extended X-ray absorption fine structure (EXAFS) results for cerium oxide show that the third $\mathrm{Ce}-\mathrm{O}$ shell is degraded and the coordination number around cerium is decreased, resulting in a decrease in the bond distances of $\boldsymbol{R}_{\mathrm{Ce}-\mathrm{O}}$ and $\boldsymbol{R}_{\mathrm{Ce}-\mathrm{Ce}}$ for particle size $<15 \mathrm{~nm}$. However, when the particle size is increased, the third $\mathrm{Ce}-\mathrm{O}$ shell started growing and the coordination number around cerium attained normal coordination. The present results provide evidence for the formation of nanocrystalline cerium oxide prepared by precipitation followed by the aging process. (C) 2000 Academic Press

Key Words: X-ray absorption spectroscopy; cerium oxide; XANES; EXAFS; nanocrystalline.

\section{INTRODUCTION}

In recent years, much effort has been devoted to the studies of the nature of bonding in rare earth compounds, $R \mathrm{O}_{2}$ and $R \mathrm{~F}_{4}$, where $R=\mathrm{Ce}, \mathrm{Pr}, \mathrm{Tb}$ etc., by many highenergy spectroscopic techniques and theoretical studies, aiming at an improved understanding of the electronic structure of these materials (1-7). In most cases, the concept of covalent mixing of $4 f$ states with anion $p$ states provided a satisfactory explanation for the observed spectra (2). Preparation of these rare earth oxides in the nanocrystalline

\footnotetext{
${ }^{1}$ To whom correspondence should be addressed. E-mail: rsliu@ccms. ntu.edu.tw. Fax: 886223636359.
}

phase has become feasible now (8-12), and as a result the drastic change in its properties $(9,13)$, viz., diffusion, mechanical, magnetic, and electrical properties with varying particle sizes, has generated a renewed interest in these materials. In addition, the possibility of using these rare earth oxides in its nanocrystalline phase as catalysts for photocatalytic reactions $(10,11,14)$, viz., oxidation of organic materials and reduction of heavy metal ions in industrial waste streams, has made it necessary to understand the structural and electronic properties of these oxides.

The techniques, viz., X-ray absorption near edge structure (XANES) and extended X-ray absorption fine structure (EXAFS), are together called X-ray absorption spectroscopy (XAS) (15). These techniques are atom specific and capable of probing the short-to-medium range structure around an imbedded or absorbing atom (10). Among the experimental techniques employed in determining the valence of rare earth ions in solid compounds, XANES studies at the rare earth $\mathrm{L}_{3}$ thresholds play an essential role due to its simplicity and universal applicability (6). Similarly, EXAFS has proved to be a powerful tool for the determination of the local structure around a specified atom in polyatomic systems $(15,16)$.

In this study, we investigated the effect of the lattice structure of cerium oxide, oxidation states of cerium, and its covalence with oxide ligands by varying the particle sizes. The cerium ion is known to have variable valence $(17,18)$ and show characteristic XANES spectra corresponding to the covalence of the bonding between cerium and oxide ligands $(1,3-6)$. Therefore, it is interesting to probe XANES to obtain the electronic properties of cerium oxide by varying the particle size. As these materials belong to the nanocrystalline phase, it is feasible to probe by EXAFS the unique structural features around $\mathrm{Ce}$ atoms in cerium oxide while varying the size of the nanoparticles.

\section{EXPERIMENTAL}

Cerium oxide for the present study was prepared by precipitation followed by the aging process at room 
temperature (19). An excess amount of ammonia solution was added to the $0.1 \mathrm{M} \mathrm{Ce}\left(\mathrm{SO}_{4}\right)_{2} \cdot 4 \mathrm{H}_{2} \mathrm{O}$ solution and the $\mathrm{pH}$ of the mixture was adjusted to 9.0. Thus, the precipitate obtained without separating the mother liquor was held for aging for 7 days. After the aging process, the precipitate was filtered, washed with distilled water, and dried at room temperature in an oven. To increase the particle sizes of $\mathrm{CeO}_{2}$, the as-prepared sample was calcined in batches at different temperatures, viz., $150,400,600$, and $800^{\circ} \mathrm{C}$ for $6 \mathrm{~h}$ in air. The $\mathrm{CeO}_{2}$ powders resulting from the calcination at a given temperature were directly used for all the measurements. For comparison, the $\mathrm{CeO}_{2}(99.99 \%)$ obtained from Cerac was also used for the measurements. The X-ray diffraction $(\mathrm{XRD})$ patterns for all the samples were recorded on a SCINTAG (X1) X-ray powder diffractometer with nickel-filtered $\mathrm{CuK} \alpha$ radiation. The particle sizes of $\mathrm{CeO}_{2}$ were calculated from the Scherrer formula using the (220) diffraction peak of respective cerium oxide (19-21). The high-resolution transmission electron microscopic (HRTEM) measurements were carried out using a Hitachi $\mathrm{H}-7100$ electron microscope operating at $100 \mathrm{kV}$. The samples for the HRTEM measurements were dispersed in alcohol before being transferred to the carbon-coated copper grids.

The XANES and EXAFS measurements for all the samples were done at room temperature in the transmission mode by using synchrotron radiation with a $\mathrm{Si}(111)$ doublecrystal monochromator at the S-05B/W20 X-ray Wiggler beam line of SRRC, Taiwan. During the measurements, the synchrotron was typically operated at an energy of $1.5 \mathrm{GeV}$ and a current between 130 and $200 \mathrm{~mA}$. The spectra were scanned in the range 5.5-6.2 keV, which covers the $\mathrm{L}_{3}$ edge absorption of cerium atoms. The photon energy was calibrated for each scan with the first inflection point of the Ce $\mathrm{L}_{3}$ edge of $\mathrm{CeO}_{2}$ (Cerac). Energy resolution was $1.5 \mathrm{eV}$ for the near edge structure and about $3.0 \mathrm{eV}$ for the EXAFS. To suppress the unwanted harmonics, the angle between the monochromator crystal faces was adjusted to mistune the incident beam by $20 \%$. Both the incident $\left(I_{0}\right)$ and transmitted $(I)$ synchrotron beam intensities were measured simultaneously in different ionization chambers filled by a mixture of nitrogen and argon gases. The fine powder samples were coated homogeneously over Scotch tape and used for the measurements. To avoid the sample thickness effect, it is required to satisfy $\Delta \mu x \leq 1$ where $\Delta \mu x$ is the edge step (22). Hence, the edge step was adjusted by controlling the number of sample-coated Scotch tape layers from the light path. The measurements were repeated until $\Delta \mu x \approx 1$.

\section{RESULTS AND DISCUSSION}

The powder X-ray diffraction patterns for cerium oxide powders calcined at different temperatures including the as-prepared sample are shown in Fig. 1. The temperature at

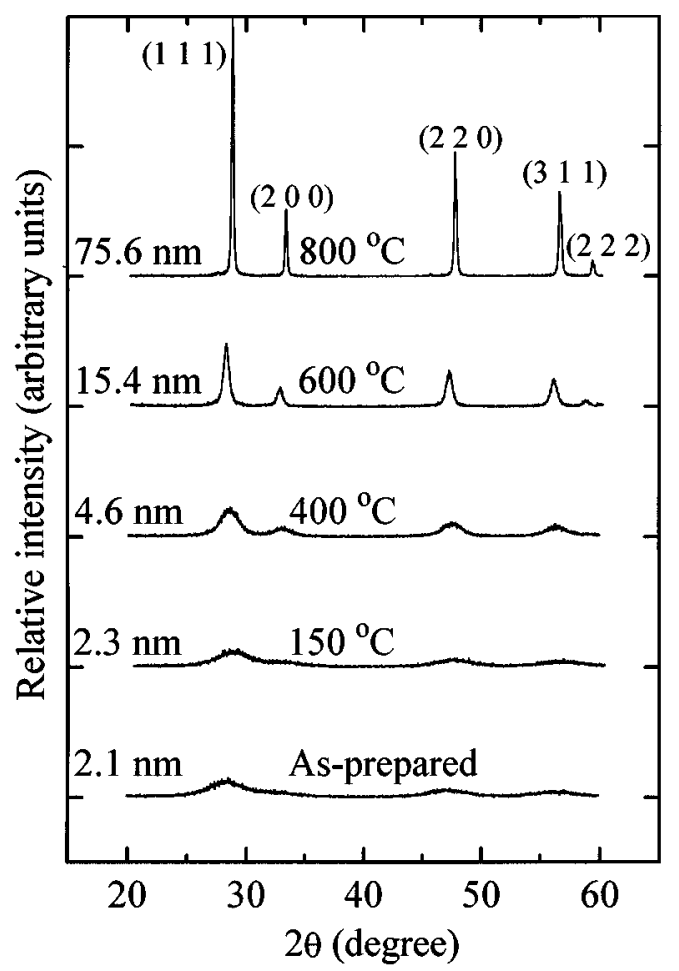

FIG. 1. Powder X-ray diffraction patterns of $\mathrm{CeO}_{2}$ samples with different particle sizes. The temperature at which the $\mathrm{CeO}_{2}$ samples were calcined and the corresponding particle sizes are indicated.

which the samples were calcined and the particle sizes obtained from the Scherrer formula and the (220) diffraction peak of cerium oxide (19-21) are also indicated in Fig. 1. The XRD pattern for the as-prepared cerium oxide powder shows a larger broadening of the peaks, which in turn leads to a small particle size. In addition, the broadening of the XRD peaks gradually decreases with increasing calcination temperature until $600^{\circ} \mathrm{C}$. With further increases of the calcination temperature to $800^{\circ} \mathrm{C}$, all the reflections of cerium(IV) oxide $\left(\mathrm{CeO}_{2}\right)$ corresponding to the cubic fluorite structure with space group $F m \overline{3} m$ and lattice constant $a=5.4 \AA$ were observed in the XRD patterns (23). Thus, in general, the XRD patterns reveal that the cerium oxide prepared by precipitation followed by the aging process retains the nanocrystalline phase, even when the samples were calcined at $600^{\circ} \mathrm{C}$. High-resolution transmission electron micrographs of $\mathrm{CeO}_{2}$ calcined at 400 and $800^{\circ} \mathrm{C}$ are reproduced in Fig. 2. The average particle sizes found in the micrographs are of the same order as obtained from XRD line-broadening analyses, which support the formation of nanocrystalline cerium oxides.

The normalized XANES spectra of cerium $\mathrm{L}_{3}$ edge for different particle sizes of cerium oxides are given in Fig. 3. The second derivatives of these XANES spectra reveal that each major band contains two components. To find out the 

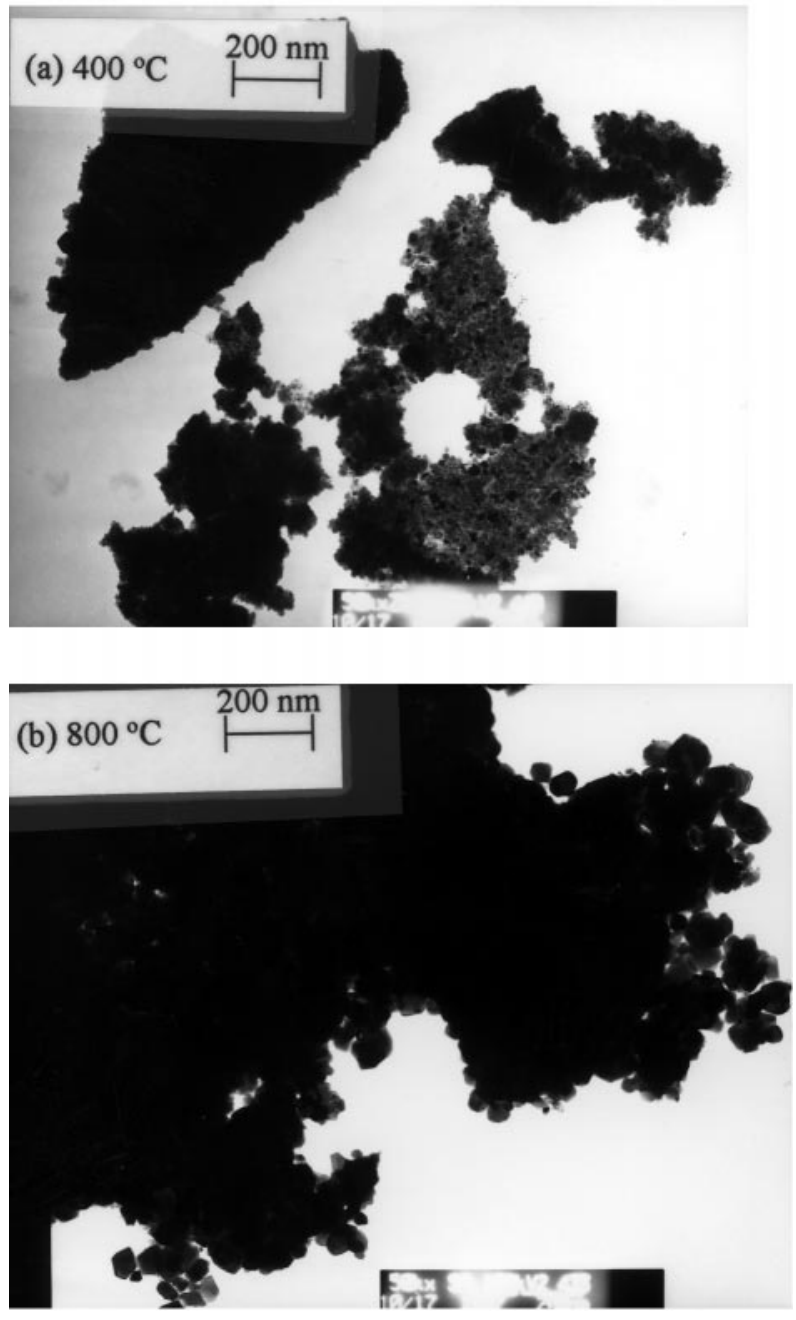

FIG. 2. High-resolution transmission electron micrographs of $\mathrm{CeO}_{2}$ calcined at (a) $400^{\circ} \mathrm{C}$ and (b) and $800^{\circ} \mathrm{C}$.

exact transition energy and the relative intensity of each transition, the XANES spectra of all the samples were fitted with Gaussian functions. To exclude the edge jump from XANES spectra, an arctan function was also included in the fit. The resultant fit to the XANES spectra in terms of Gaussian and arctan functions are reproduced in Fig. 4 for $\mathrm{CeO}_{2}(75.6 \mathrm{~nm})$ as a representative example. The assignments for all the transitions are made based on the earlier works on $\mathrm{CeO}_{2}$ and $\mathrm{PrO}_{2}$ (1-6). The component $\mathrm{A}$ (with its subpeak $\mathrm{A}_{1}$ and $\mathrm{A}_{2}$ ) is assigned to a core-excited $\mathrm{Ce}^{\mathrm{IV}}$ final state with the configuration $2 p 4 f^{0} 5 d^{*}$, where, $2 p$ denotes a hole in the $2 p$ shell (with $J=3 / 2$ ), while $5 d^{*}$ refers to the excited electron in the $5 \mathrm{~d}$ state. The components $\mathrm{A}_{1}$ and $\mathrm{A}_{2}$ correspond to the crystal field split of the $2 p 4 f^{0} 5 d^{*}$ final state. Component $\mathrm{B}$ then corresponds mainly to a $2 p 4 f^{1}$ $5 d^{*} \underline{L}$ state, where $\underline{L}$ stands for a hole in the anion ligand orbital. In $\mathrm{CeO}_{2}$, component $\mathrm{B}$ has more spectral weight than the sum of components $\mathrm{A}_{1}$ and $\mathrm{A}_{2}$, reflecting the relative small ionicity of the tetravalent ground state of this compound. It is found that the relative intensity of the transition $\mathrm{C}$ increases with calcination temperature. Based on these observations and the earlier works, transition $\mathrm{C}$ is assigned to a $\mathrm{Ce}^{3+}$ impurity $(1-6,17,18)$. The weak feature $\mathrm{D}$ in the pre-edge region is explained by a dipole-forbidden $2 p_{3 / 2} \rightarrow 4 f$ transition, which is a consequence of $5 d$ admixtures to the $4 f$ state. The changes induced by the different particle sizes of $\mathrm{CeO}_{2}$ on individual components, A-D, resulting from the fit analyses, are as follows. With increasing calcination temperature and in turn particle size, the relative intensity of transition $\mathrm{B}$ increases. Component $\mathrm{C}$ shows an increase in its intensity and reaches its maximum with a particle size of $\sim 15 \mathrm{~nm}$ and then decreases with further increases of particle size. Components $\mathrm{A}$ and $\mathrm{B}$ shift toward higher energies, while transition $\mathrm{C}$ shifts slightly toward lower energy with increasing particle size. As a consequence, the separation between transitions $\mathrm{B}$ and $\mathrm{C}$ increases, amounting to $0.65 \mathrm{eV}$ with increasing particle size which is due to increasing calcination temperature. No changes in the relative energies of the transitions, $A_{1}, A_{2}$, and $\mathrm{B}$ were found within the present accuracy. To quantify the results, the intensity ratios of the components, viz., $\left(I_{\mathrm{B}} / I_{\mathrm{A}}\right)$, and the energy difference between the components $\mathrm{B}$ and $\mathrm{C}$, viz., $\Delta E(\mathrm{~B}, \mathrm{C})$ are plotted versus the particle size in Fig. 5. Both the intensity ratio, $\left(I_{\mathrm{B}} / I_{\mathrm{A}}\right)$, and the energy difference, $\Delta E(\mathrm{~B}, \mathrm{C})$, show a systematic increase with increasing particle size until $\sim 15 \mathrm{~nm}$, but further increases in particle sizes do not show a significant change in these parameters. In covalent compounds like $\mathrm{CeO}_{2}$, one would expect an increase of covalence between $\mathrm{Ce}(4 f)$ and $\mathrm{O}(p)$ with increasing particle size. This in turn would cause an

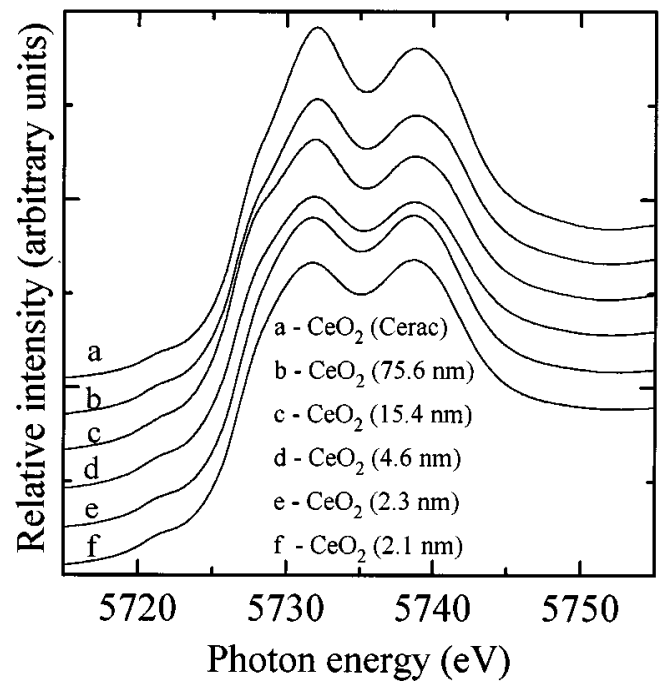

FIG. 3. The normalized XANES spectra of $\mathrm{CeO}_{2}$ samples with different particle sizes. The base lines are shifted for clarity. 


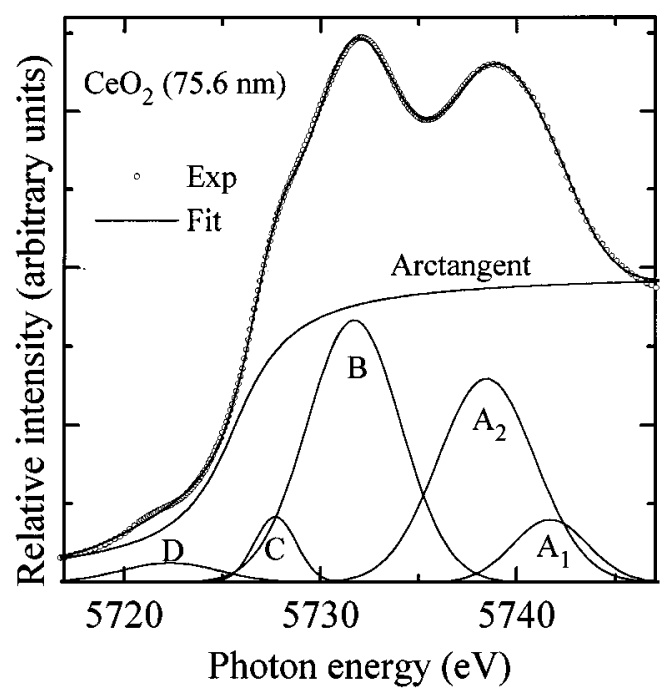

FIG. 4. A theoretical fit of XANES spectra of $\mathrm{CeO}_{2}(75.6 \mathrm{~nm})$ as a representative example.

increase in the relative intensity of the transition to $2 p 4 f^{1} 5 d^{*} \underline{L}$ final state and its transition energy would shift toward higher energy in the $\mathrm{L}_{3}$ XANES spectra. This was indeed found to be the case. These results are also in accordance with the earlier reports on $\mathrm{CeO}_{2}$ and $\mathrm{PrO}_{2}$ with

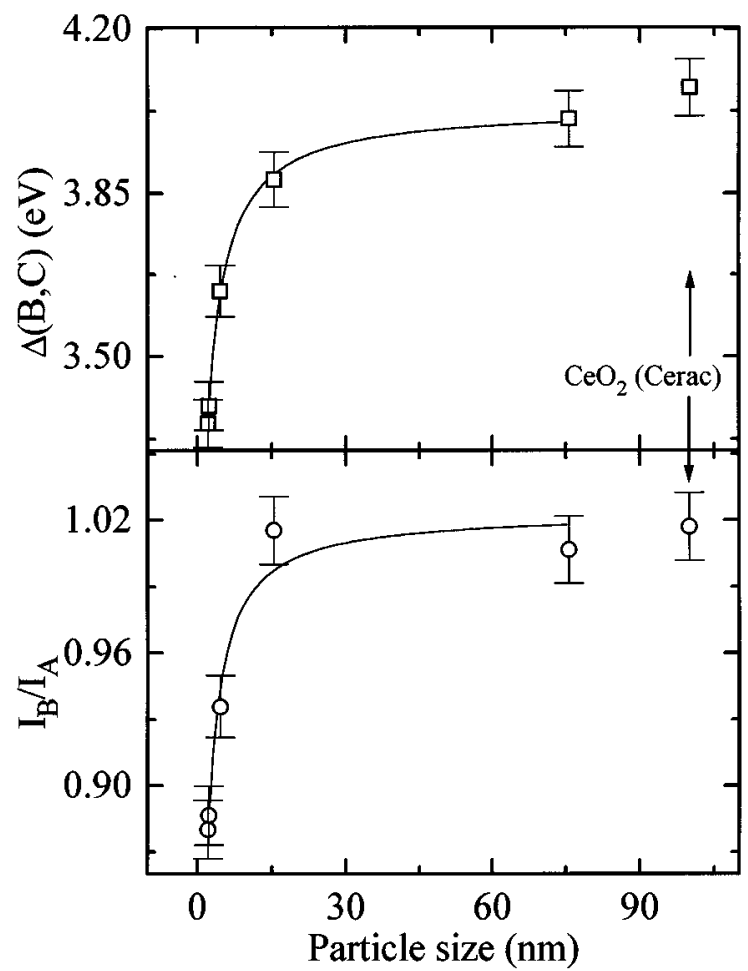

FIG. 5. Plots of the intensity ratios of the bands $\left(I_{\mathrm{B}} / I_{\mathrm{A}}\right)$ and the energy difference of the bands $(\triangle E(\mathrm{~B}, \mathrm{C}))$ in the XANES spectra of $\mathrm{CeO}_{2}$ as a function of particle sizes. The solid lines are guides to the eyes. pressure-induced changes (1-6). The change in the relative intensity of component $\mathrm{C}$ as a function of particle size is indicative of the variation in concentrations of $\mathrm{Ce}^{3+}$ impurity in a $\mathrm{CeO}_{2}$ matrix. The present XANES spectral data on $\mathrm{CeO}_{2}$ show that all the $\mathrm{CeO}_{2}$ samples of the present study, including the $\mathrm{CeO}_{2}$ obtained from Cerac, contain a minimum $5 \%$ of $\mathrm{Ce}^{3+}$ as an impurity.

For the analysis of the EXAFS data, a backgroundsubtraction method was used for the data processing (24). It uses the criteria of good background removal, the optimization of the low $r$ portion of the EXAFS and Fourier transformed to $r$ space. The normalized EXAFS obtained is

$$
\chi(k)=\frac{\mu(k)-\mu_{0}(k)}{\Delta \mu_{0}(0)}
$$

where $k$ is the wavenumber, $\mu(k)$ is the measured absorption, $\mu_{0}(k)$ is the background, and $\Delta \mu_{0}(0)$ is the edge step. The value of $E_{0}$ was estimated from the respective first inflection points found in the derivative of cerium $\mathrm{L}_{3}$-edge absorption spectra for each sample and they were used as input parameters for the background subtraction. Phase-corrected Fourier transforms of $\chi(k)$ to $r$ space with a $k^{3}$ weighting factor and a Hanning window function $(\mathrm{D} k 1$ and $\mathrm{D} k 2=$ $0.1)$ were performed. The values for $k_{\min }\left(\AA^{-1}\right)$ and $k_{\max }$ $\left(\AA^{-1}\right)$ are $\sim 3.7$ and $\sim 9.3$, respectively. The value of the passive electron reduction factor, $S_{0}^{2}(25)$, was deduced from the cerium $\mathrm{L}_{3}$-edge EXAFS of $\mathrm{CeO}_{2}$ (Cerac) with known structural data (23) and it was used for fitting the EXAFS data for $\mathrm{CeO}_{2}$ in the present study. The theoretical calculation of the scattering amplitudes and phase shift functions of $\mathrm{CeO}_{2}$ were done by using the $\operatorname{FEFF}(7.02)$ program $(26,27)$. The shells are due to single scattering corresponding to $\mathrm{Ce}-\mathrm{O}$ (first shell, $2.344 \AA$ ), $\mathrm{Ce}-\mathrm{Ce}$ (second shell, $3.827 \AA$ ), and Ce-O (third shell, $4.487 \AA$ ) (23), which largely contribute to the intensity.

The phase-corrected and Fourier-transformed cerium $\mathrm{L}_{3}-$ edge EXAFS spectra of cerium oxide with different particle sizes are reproduced in Fig. 6. The main observation which can be made from the data in Fig. 6 is that there is a general enhancement in amplitude of the Fourier-transformed intensity with increasing particle size of cerium oxide. These changes indicate that the nearest $(\mathrm{Ce}-\mathrm{O})$ and next nearest neighbor $(\mathrm{Ce}-\mathrm{Ce})$ shells experience a decrease in mean square relative displacement (MSRD) with increasing particle size. Similar observations have also been made for nanocrystalline $\mathrm{TiO}_{2}$ and $\mathrm{CdS}(10,28)$. In general, to get more insight into the structural properties of these oxides, detailed analyses of the experimental EXAFS spectra may be conducted by the theoretical fits. However, in the present case, the theoretical fit of the experimental EXAFS could not be done without uncertainty due to the contributions from the final-sate mixed valence behavior $(4,29-31)$ and 


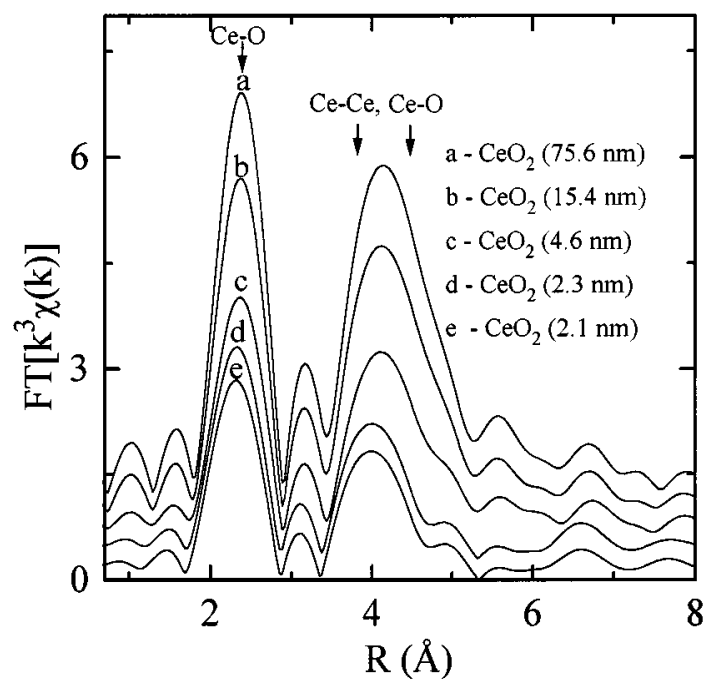

FIG. 6. The phase-corrected and Fourier-transformed EXAFS signals of $\mathrm{CeO}_{2}$ with different particle sizes. The base lines are shifted for clarity.

intense multielectron excitations (31-33) of cerium oxide to the EXAFS signal at the $\mathrm{L}_{3}$ edge of cerium. These effects can be excluded by recording the EXAFS at the $\mathrm{K}$ edge of cerium. With available energy range, the EXAFS signal at the K edge of cerium cannot be recorded with S-05B/W20 $\mathrm{X}$-ray Wiggler beam line of SRRC. However, as the present study deals with the X-ray absorption spectra of $\mathrm{CeO}_{2}$ by varying the particle size, one may obtain relative estimates of the structural parameters around cerium using cerium $\mathrm{L}_{3}$-edge absorption spectra. The experimental EXAFS data for the $\mathrm{L}_{3}$ edge of cerium were fitted with the theoretical EXAFS function using the FEFFIT (2.52d) (34) program by ignoring the effects of the final-state mixed valence behavior $(4,29-31)$ and intense multielectron excitations (31-33) of cerium oxide to the EXAFS signal. However, the structural information should be taken with caution. The goodness of the fit has been judged by means of $\chi^{2}$, reduced $\chi^{2}\left(\chi_{v}^{2}\right)$, and $R$ factor discussed elsewhere $(35,36)$. In the present study, the reduced $\chi^{2}$ s and $R$ factors were found to be $<50$ and $<0.3 \%$, respectively. The coordination numbers $(N)$, bond distances $\left(R_{\mathrm{Ce}-\mathrm{O} / \mathrm{Ce}-\mathrm{Ce}}\right)$ and Debye-Waller factors $\left(\sigma_{\mathrm{Ce}-\mathrm{O} / \mathrm{Ce}-\mathrm{Ce}}^{2}\right)$ (37) obtained from EXAFS fits for $\mathrm{CeO}_{2}$ as a function of calcination temperatures and the resulting particle sizes are given in Table 1 . The as-prepared cerium oxide $(2.1 \mathrm{~nm})$ and the sample calcined at $150^{\circ} \mathrm{C}(2.3 \mathrm{~nm})$ seem to have no contribution from the $\mathrm{Ce}-\mathrm{O}$ (third shell). This is also seen in Fig. 6 where the relative intensity of the EXAFS band at $\sim 4 \AA$ is drastically reduced when compared to the band at $\sim 2.3 \AA$ with decreasing particle size. In addition, the coordination number $(N)$ around cerium in the $\mathrm{Ce}-\mathrm{O}$ (first shell) and $\mathrm{Ce}-\mathrm{Ce}$ (second shell) is also reduced with a particle size lower than $\sim 15 \mathrm{~nm}$. However, when the particle size is increased, the third $\mathrm{Ce}-\mathrm{O}$ shell started growing and the coordination number around cerium attained normal coordination. The reduction in the bond distances observed for $R_{\mathrm{Ce}-\mathrm{O}}$ and $R_{\mathrm{Ce}-\mathrm{Ce}}$ provide evidence for a decrease in the coordination around the cerium atom in cerium oxide with the particle size $<15 \mathrm{~nm}$. However, further increases of the particle size had an insignificant effect on $R_{\mathrm{Ce}-\mathrm{O}}$ and $\mathrm{R}_{\mathrm{Ce}-\mathrm{Ce}}$. A decreasing trend observed for the values of the Debye-Waller factors with increasing particle sizes can be understood as the nanocrystalline cerium oxide changing to a more ordered crystalline phase. Similar results were also found for nanocrystalline $\mathrm{TiO}_{2}$ where the reduction of bond distance was accompanied with lowering of coordination (10).

\section{CONCLUSION}

The powder X-ray diffraction patterns for nanocrystalline cerium oxide show that the cerium oxide prepared by precipitation followed by the aging process retains the $\mathrm{CeO}_{2}$ in the nanocrystalline phase, even when the samples were

TABLE 1

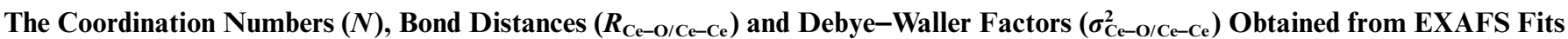
for $\mathrm{CeO}_{2}$ as a Function of Calcination Temperatures and the Resulting Particle Sizes (The Values in the Parentheses Are Errors)

\begin{tabular}{|c|c|c|c|c|c|c|c|c|c|c|}
\hline \multicolumn{2}{|c|}{$\mathrm{CeO}_{2}$} & \multicolumn{3}{|c|}{ Ce-O (First shell) } & \multicolumn{3}{|c|}{$\mathrm{Ce}-\mathrm{Ce}$ (Second shell) } & \multicolumn{3}{|c|}{$\mathrm{Ce}-\mathrm{O}$ (Third shell) } \\
\hline $\begin{array}{l}\text { Calcination } \\
\text { temperature }\left({ }^{\circ} \mathrm{C}\right)\end{array}$ & $\begin{array}{c}\text { Particle size } \\
(\mathrm{nm} \pm 1)\end{array}$ & $N$ & $R(\AA)$ & $\sigma^{2}\left(10^{-3} \AA^{2}\right)$ & $N$ & $R(\AA)$ & $\sigma^{2}\left(10^{-3} \AA^{2}\right)$ & $N$ & $R(\AA)$ & $\sigma^{2}\left(10^{-3} \AA^{2}\right)$ \\
\hline As-prepared & 2.1 & 6 & $2.280(12)$ & $6.6(9)$ & 6 & $3.800(15)$ & $4.9(8)$ & $\ldots$ & $\ldots$ & $\ldots$ \\
\hline 150 & 2.3 & 6 & $2.285(11)$ & $6.0(8)$ & 6 & $3.806(14)$ & $4.5(8)$ & $\ldots$ & $\ldots$ & $\ldots$ \\
\hline 400 & 4.6 & 6 & $2.313(12)$ & $5.0(9)$ & 9 & $3.845(12)$ & $3.8(8)$ & 16 & $4.421(31)$ & $11.2(9)$ \\
\hline 600 & 15.4 & 8 & $2.324(12)$ & $4.5(9)$ & 12 & $3.848(12)$ & $2.8(8)$ & 24 & $4.421(28)$ & $10.3(9)$ \\
\hline 800 & 75.6 & 8 & $2.331(13)$ & $3.0(9)$ & 12 & $3.852(12)$ & $1.5(8)$ & 24 & $4.434(30)$ & $9.2(9)$ \\
\hline Cryst. data ${ }^{a}$ & $\ldots$ & 8 & 2.344 & $\ldots$ & 12 & 3.827 & $\ldots$ & 24 & 4.487 & $\ldots$ \\
\hline
\end{tabular}

${ }^{a}$ The crystal structure data were obtained from Ref. 23. 
calcined at $600^{\circ} \mathrm{C}$. The analyses of the XANES spectra for $\mathrm{CeO}_{2}$ show that the increase in the relative intensity of the transition to $2 p 4 f^{1} 5 d^{*} \underline{L}$ final state and the transition energy shifts toward higher energy are due to the increase in covalence of $\mathrm{Ce}-\mathrm{O}$ with increasing particle size. In addition, these studies show that all the $\mathrm{CeO}_{2}$ samples for the present study, including the $\mathrm{CeO}_{2}$ obtained from Cerac, contain a minimum $5 \%$ of $\mathrm{Ce}^{3+}$ as an impurity. The EXAFS results for $\mathrm{CeO}_{2}$ show that the third $\mathrm{Ce}-\mathrm{O}$ shell is degraded and the coordination number around cerium is decreased when the particle size is $<15 \mathrm{~nm}$. However, when the particle size is increased, the third $\mathrm{Ce}-\mathrm{O}$ shell started growing and the coordination number around cerium attained normal coordination. The present XRD, XANES, and EXAFS results with variation of the particle size provide evidence in support of the formation of nanocrystalline $\mathrm{CeO}_{2}$ prepared by precipitation followed by the aging process.

\section{ACKNOWLEDGMENT}

We thank all the members at SRRC for their technical support. This research is financially supported by the National Science Council of the Republic of China under Grant 86-CPC-E-002-002.

\section{REFERENCES}

1. L. Douillard, M. Gautier, N. Thromat, M. Hentriot, M. J. Guittet, J. P. Duraud, and G. Tourillon, Phys. Rev. B 49, 16171 (1994).

2. Z. Hu, S. Bertram, and G. Kaindl, Phys. Rev. B 49, 39 (1994) and references therein.

3. H. Dexpert, R. C. Karnatak, J. M. Esteva, J. P. Connerade, M. Gasgnier, P. E. Caro, and L. Albert, Phys. Rev. B 36, 1750 (1987).

4. A. V. Soldatov, T. S. Ivanchenko, S. Della Longa, A. Kotani, Y. Iwamoto, and A. Bianconi, Phys. Rev. B 50, 5074 (1994).

5. L. Douillard, M. Gautier, N. Thromat, and J. P. Duraud, Nucl. Instr. Methodol. B 97, 133 (1995).

6. G. Kaindl, G. Schmiester, and E. V. Sampathkumaran, Phys. Rev. B 38, 10174 (1988).

7. K. Asakura, Y. Satow, and H. Kuroda, J. Phys. C 8, 185 (1986).

8. M. Winterer, R. Nitsche, and H. Hahn, J. Phys. IV France 7, C2-1211 (1997).

9. R. Nitsche, M. Winterer, M. Croft, and H. Hahn, Nucl. Instr. Methodol. B 97, 127 (1995).
10. V. Luca, S. Djajanti, and R. F. Howe, J. Phys. Chem. B 102, 10650 (1998) and references therein.

11. L. X. Chen, T. Rajh, Z. Wang, and M. C. Thurnauer, J. Phys. Chem. B 101, 10688 (1997) and references therein.

12. G. Antonioli, D. Bersani, P. P. Lottici, G. Gnappi, and A. Montenero, Nucl. Instr. Meth. B 97, 198 (1995).

13. S. Chen, T. Ida, and K. Kimura, J. Phys. Chem. B 102, 6169 (1998).

14. C. Lamberti, S. Bordiga, D. Arduino, A. Zecchina, F. Geobaldo, G. Spanó, F. Genoni, G. Petrini, A. Carati, F. Villain, and G. Vlaic, J. Phys. Chem. B 102, 6382 (1998).

15. Y. Iwasawa, "X-Ray Absorption Fine Structure for Catalysts and Surfaces." World Scientific, New Jersey, 1996.

16. A. Borgna, S. M. Stagg, and D. E. Resasco, J. Phys. Chem. B 102, 5077 (1998).

17. S. L. Lin, C. S. Hwang, and J. F. Lee, J. Mater. Res. 11, 2641 (1996).

18. S. L. Lin, C. S. Hwang, and J. F. Lee, Jpn. J. Appl. Phys. 35, 3975 (1996).

19. M. Hiano and E. Kato, J. Mater. Sci. Lett. 15, 1249 (1996).

20. A. R. West, "Solid State Chemistry and Its Applications." John Wiley and Sons, New York, 1986.

21. Y. C. Zhou and M. N. Rahaman, J. Mater. Res. 8, 1680 (1993).

22. E. A. Stern and K. Kim, Phys. Rev. B 23, 3781 (1981).

23. M. Wolcyrz and L. Kepinski, J. Solid State Chem. 99, 409 (1992).

24. M. Newville, P. Livins, Y. Yacoby, J. J. Rehr, and E. A. Stern, Phys. Rev. B 47, 14126 (1993).

25. E. A. Stern and S. M. Heald, in "Handbook on Synchrotron Radiation" (E. E. Koch, Ed.), Vol. 1. North-Holland, York, 1983.

26. A. L. Ankudinov and J. J. Rehr, Phys. Rev. B 56, R1712 (1997).

27. A. L. Ankudinov, "Relativistic Spin-Dependent X-ray Theory." Ph.D. Thesis, University of Washington, 1996.

28. J. Rockenberger, L. Tröger, A. Kornowski, T. Vossmeyer, A. Eychmüller, J. Feldhaus, and H. Weller, J. Phys. Chem. 101, 2691 (1997).

29. A. Bianconi, A. Marcelli, H. Dexpert, R. C. Karnatak, A. Kotani, T. Jo, and J. Petiau, Phys. Rev. B 35, 806 (1987).

30. D. Malterre, Phys. Rev. B 43, 1391 (1990).

31. J. A. Solera, J. García, and M. G. Proietti, Phys. Rev. B 51, 2678 (1995).

32. J. Chaboy, J. García, A. Marcelli, and M. F. Ruiz-López, Chem. Phys. Lett. 174, 389 (1990).

33. J. Chaboy, A. Marcelli, and T. A. Tyson, Phys. Rev. B 49, 11652 (1994).

34. E. A. Stern, M. Newville, B. D. Ravel, Y. Yacoby, and D. Haskel, Physica B 208 and 209, 117 (1995).

35. P. R. Bevington, "Data Reduction and Error Analysis for the Physical Sciences." McGraw-Hill, New York, 1969.

36. W. H. Press, S. A. Teulosky, W. T. Vetterling, and B. P. Flannery, "Numerical Recipes." Cambridge University Press, New York, 1992.

37. E. D. Crozier, J. J. Rehr, and R. Ingalls, in "X-Ray Absorption: Principles, Applications Techniques of EXAFS, SEXAFS and XANES" (D. C. Koningsberger and R. Prins, Eds.), Chap. 9. John Wiley \& Sons, New York, 1988. 